\title{
BIORREMEDIAÇÃO VEGETAL DO ESGOTO DOMICILIAR: O CASO DA FOSSA VERDE EM COMUNIDADES RURAIS DO ALTO SERTÃO ALAGOANO
}

\author{
A.P.Oliveira Netto $^{1 *}$; L.R.M.Guerra ${ }^{1}$; M.R.P.Silva ${ }^{1}$ e R.F.Silva ${ }^{1}$ \\ 1 Universidade Federal de Alagoas - UFAL Campus Sertão, Delmiro Gouveia-AL, Brasil \\ *oliveira_netto@hotmail.com
}

\section{RESUMO}

O imenso déficit de atendimento referente a cobertura de coleta e tratamento do esgoto requer desenvolvimento de sistemas que combinam destinação adequada dos efluentes e baixos custos de construção e operação. Nesse contexto surge a biorremediação vegetal, através da fossa verde, tecnologia social sustentável e de baixo custo, apresentando-se como alternativa viável principalmente para a zona rural de municípios. Essa tecnologia social objetiva contribuir para o enfrentamento da problemática do esgoto domiciliar e das suas consequências para a saúde coletiva da comunidade e para o meio ambiente; sendo alternativa de destinação do esgoto doméstico, além de possibilitar o cultivo de algumas espécies frutíferas.
\end{abstract}

Mediante parceria estabelecida com o projeto Renas-Ser que atua na linha de gestão de corpos hídricos superficiais e subterrâneos, três unidades de fossa verde encontram-se construídas e em fase inicial de operação em comunidades rurais de municípios do alto sertão alagoano, contemplando o condicionamento adequado dos efluentes domésticos. Os primeiros resultados da observação pontual de redução de matéria orgânica são bastante animadores, tendo em vista a remoção de aproximadamente $38 \%$ da DQO já na primeira camada suporte. A etapa seguinte consiste na definição dos demais parâmetros a serem monitorados e verificar a aprovação dos usuários da tecnologia.

PALAVRAS-CHAVE: saúde pública, material suporte, tratamento anaeróbio.

\section{BIOREMEDIATION OF DOMESTIC SEWAGE: THE CASE OF GREEN SEPTIC TANK IN ARID RURAL COMMUNITIES OF ALAGOAS.}

\section{ABSTRACT}

The deficit regarding the coverage of collection and treatment of sewage requires systems that combine proper disposal of wastewater and low construction and operating costs. In this context the bioremediation through the green septic tank, sustainable social and low cost technology, presents itself as a viable alternative especially for rural municipalities. This objective social technology contribute to confronting the domestic sewage problem and its consequences for public health and the environment; It is alternative for allocation of domestic sewage, as well as allowing the cultivation of some fruit species. Through partnership with the project
\end{abstract}

Renas-Ser engaged in the management of surface and underground water bodies, three green septic tanks were constructed and are in the initial phase of operation in arid rural communities of Alagoas, contemplating the proper conditioning of domestic sewage. The first results of reduction in organic matter are very encouraging, with a view to removing approximately $38 \%$ of COD on the first support layer. The next phase is to define the others parameters to monitor and verify the approval of users of the technology.

KEYWORDS: public health, support material, anaerobic treatment. 


\section{INTRODUÇÃO}

O Brasil, com população total de cerca de 200 milhões de habitantes apresenta um déficit de atendimento no que se refere a cobertura de coleta e tratamento de esgoto sanitário. Segundo o Sistema Nacional de Informações sobre Saneamento (SNIS, 2013), os índices de saneamento indicam que de todo o esgoto gerado, apenas 39\% recebe algum tipo de tratamento, o restante vai direto para a natureza. Esses indicadores ficam ainda mais drásticos na região nordeste, onde a coleta de esgoto na zona urbana é de $29,3 \%$ e apenas $28,8 \%$ do gerado é tratado (SNIS, 2013).

Há um grande desequilíbrio regional entre os beneficiados com sistemas de esgotos sanitários. Por exemplo, enquanto no sudeste tem-se $58 \%$ da população beneficiada, na Região Norte este índice cai para menos de 2,5\% com ligações de esgotos sanitários (MOREIRA, 2008). Diante desses números que avançam vagarosamente, Tsutiya (2000) ressalta que muitas obras de coleta e transporte de esgoto deverão ser construídas no país, para a melhoria de vida da população.

Nações pobres e em desenvolvimento, como o Brasil, são as que mais sofrem com doenças relacionadas a sistemas de água e de esgoto inadequados. O Instituto Trata Brasil relata que em 2013, segundo informações do DataSus, foram notificadas mais de 340 mil internações por infecções gastrintestinais em todo o país, relacionadas as deficiências de saneamento básico. O mais preocupante é o fato de que a maior parte dessas internações ocorreu nas áreas com menor acesso ao esgotamento sanitário: Norte e Nordeste, gerando outras consequências de impacto extremamente negativo na qualidade e expectativa de vida da população. Geralmente essas doenças se devem a ausência de água em quantidade satisfatória ou a sua qualidade imprópria para o consumo (DI BERNARDO \& DANTAS, 2005).

Em termos de investimentos, o Instituto Trata Brasil apresenta dados do Plano Nacional de Saneamento Básico (PLANAB) que assegura que o custo para universalizar o acesso aos 4 (quatro) serviços de saneamento (água, esgoto, resíduos e drenagem) é de $\mathrm{R} \$ 508$ bilhões, no período de 2014 a 2033. Para universalização da água e dos esgotos esse custo será de R \$ 303 bilhões em 20 anos.

Os esgotos domésticos contem aproximadamente $99,9 \%$ de água. A fração restante da sua composição inclui sólidos orgânicos e inorgânicos, suspensos ou dissolvidos, bem como microrganismos. Portanto, é devida a essa fração de $0,1 \%$, numericamente tão pequena, que há necessidade de se tratar os esgotos (VON SPERLING, 2005). Ela é causadora dos mais desagradáveis transtornos, pois a mesma possui em seu meio, microrganismos, na maioria unicelulares, consumidores de matéria orgânica e de oxigênio e, muito provavelmente, a ocorrência de patogênicos a vida animal em geral (EMBASA, 2008).

A consciência crescente de que o tratamento de águas residuais é de vital importância para a saúde pública e para o combate a poluição das águas de superfície e submersas levou a necessidade de se desenvolver sistemas que combinam alta eficiência de remoção de matéria orgânica a custos baixos de construção e de operação que consigam combater esses problemas gerados pelo não tratamento dos efluentes. Estes, quando não tratados, lançados ao meio ambiente podem comprometer gravemente a saúde publica. Nos últimos tempos surgiram várias pesquisas e soluções para desenvolvimento de processos de tratamento de esgotos mais eficientes dentro dos grandes centros urbanos, que por sua grande população, deve-se pensar em maneiras mais compactas de tratamento. Nos países em desenvolvimento, por possuírem baixo poder aquisitivo, e nas nações desenvolvidas, por apresentarem pequenas áreas disponíveis em seus centros urbanos, convém fazer uso da tecnologia anaeróbia (OLIVEIRA NETTO, 2007).

Há basicamente duas variantes dos sistemas de esgotamento sanitário. O sistema individual - solução no local, individual ou para poucas residências e o sistema coletivo - solução com 
afastamento dos esgotos da área servida (VON SPERLING et al, 1995 a, apud VON SPERLING, 2005). A fossa verde enquadra-se no sistema individual, normalmente atendendo a unidades uni familiares, no entanto, há possibilidade de adequar o sistema a unidades coletivas como já realizado em municípios alagoanos, bem como em assentamentos rurais de outros estados.

A opção por essa tecnologia e a crescente aceitação por seu uso pela comunidade atestam a viabilidade da alternativa. Hoje ela é utilizada principalmente na zona rural e é apresentada no sistema de biorremediação vegetal usado na fossa verde onde é realizado o tratamento do esgoto domestico através da tecnologia anaeróbia e desenvolvimento de biomassa em material suporte.

Biorremediação é um processo no qual organismos vivos, normalmente plantas ou microrganismos, são utilizados tecnologicamente para remover ou reduzir (remediar) poluentes no ambiente (GAYLARDE, 2005). Também é chamada de biotecnologia ambiental, por usar, de forma controlada, processos microbiológicos que ocorrem normalmente na natureza para remover poluentes. A tecnologia configura uma alternativa atraente para a zona rural de Alagoas, proporcionando qualidade de vida e saúde para todos os beneficiados, com condicionamento correto do efluente, além de possuir baixo custo de implantação, reduzindo a probabilidade de ocorrência de doenças relacionadas com o esgoto a céu aberto.

Diante do estudo bibliográfico realizado e do sucesso na implantação e operação do sistema comprovado em outros estudos percebeu-se a possibilidade e viabilidade técnica de implantação da tecnologia na região do entorno da UFAL - Campus Sertão, efetivando o âmbito da extensão universitária, tendo em vista $\mathrm{s}$ utilização de mão de obra local como o intuito de difundir o conhecimento sobre a tecnologia. A possibilidade tornou-se viável graças à parceria estabelecida com o Projeto Renas-Ser que atua na área de gestão de corpos hídricos superficiais e subterrâneos sendo patrocinado pela Petrobras, proposto pela Organização de Preservação Ambiental (OPA), com o apoio do Instituto Palmas e parceria das Prefeituras Municipais das cidades contempladas.

O Projeto Renas-Ser atua em três municípios do alto sertão de Alagoas: Água Branca, Mata Grande e Pariconha. Os mesmos apresentam condição diferenciada em relação aos outros municípios do alto sertão. Ficam entre serras e com algumas comunidades rurais com uma quantidade significativa de fontes (nascentes de água) que suprem parcialmente ou por vezes totalmente o abastecimento de água de famílias e até de comunidades. Essas nascentes requerem gerenciamento e manejo adequado para que os efluentes domésticos gerados no entorno não venham a poluí-las, tendo em vista que o sistema de esgotamento sanitário não atende nem a população da zona urbana desses municípios.

Na parceria estabelecida, a UFAL entrou com a parte técnica, o Projeto Renas-Ser com o financiamento e a comunidade com parte da mão de obra e como futuros multiplicadores da tecnologia. Assim, cada município foi contemplado com uma unidade, implantada em comunidades rurais, sendo uma delas comunidade indígena. As três unidades já foram construídas e encontram-se em início de operação. A etapa seguinte consiste na definição dos parâmetros a serem analisados para o acompanhamento da eficiência de tratamento ao longo das camadas de material suporte.

\section{MATERIAIS E MÉTODOS}

A fossa verde (canteiro biosséptico) consiste na construção de uma vala de alvenaria impermeabilizada com dimensões variáveis, apresentando uma estrutura interna em forma de câmara onde os blocos cerâmicos são colocados deitados em camadas determinadas com os furos abertos para a superfície preenchida com material filtrante, conforme Figuras 1 e 2 . A técnica foi desenvolvida pela Universidade Federal do Ceará (UFC), implantada no estado e trazida para o sertão do estado de Alagoas por questões de similaridade climática em termos de temperatura e 
precipitação, fatores que influenciam seu funcionamento (OLIVIERA NETTO et al., 2012). Municípios como Murici, São José da Tapera e Pão de Açúcar apostaram na tecnologia social com o intuito de suprir as deficiências do correto condicionamento dos despejos domésticos, principalmente as comunidades rurais.

O esgoto é direcionado para dentro da câmara, caracterizado por ser um meio anaeróbio e, em seguida, passa a escoar para a parte externa dessa estrutura, que deve ser preenchida por materiais porosos e inertes que servem como filtro, tais como entulho e material terroso de granulometria variada, onde são cultivadas algumas espécies frutíferas (GALBIATI, 2009). O tratamento do efluente na fossa ocorre em fluxo ascendente permitindo que os sólidos orgânicos estejam em contato máximo como o material suporte que é um dos pontos chave para a retenção da biomassa. $\mathrm{O}$ despejo do esgoto é feito na base da fundação, surgindo à formação do lodo em forma de massa microbiana que se estende ao longo do material suporte (GABIALTI, 2009). É importante enfatizar que as condições químicas e principalmente de temperatura afetam bruscamente no metabolismo das bactérias. Sendo as regiões tropicais mais apropriadas para o melhor funcionamento operacional do sistema com temperaturas acima de $20^{\circ} \mathrm{C}$.

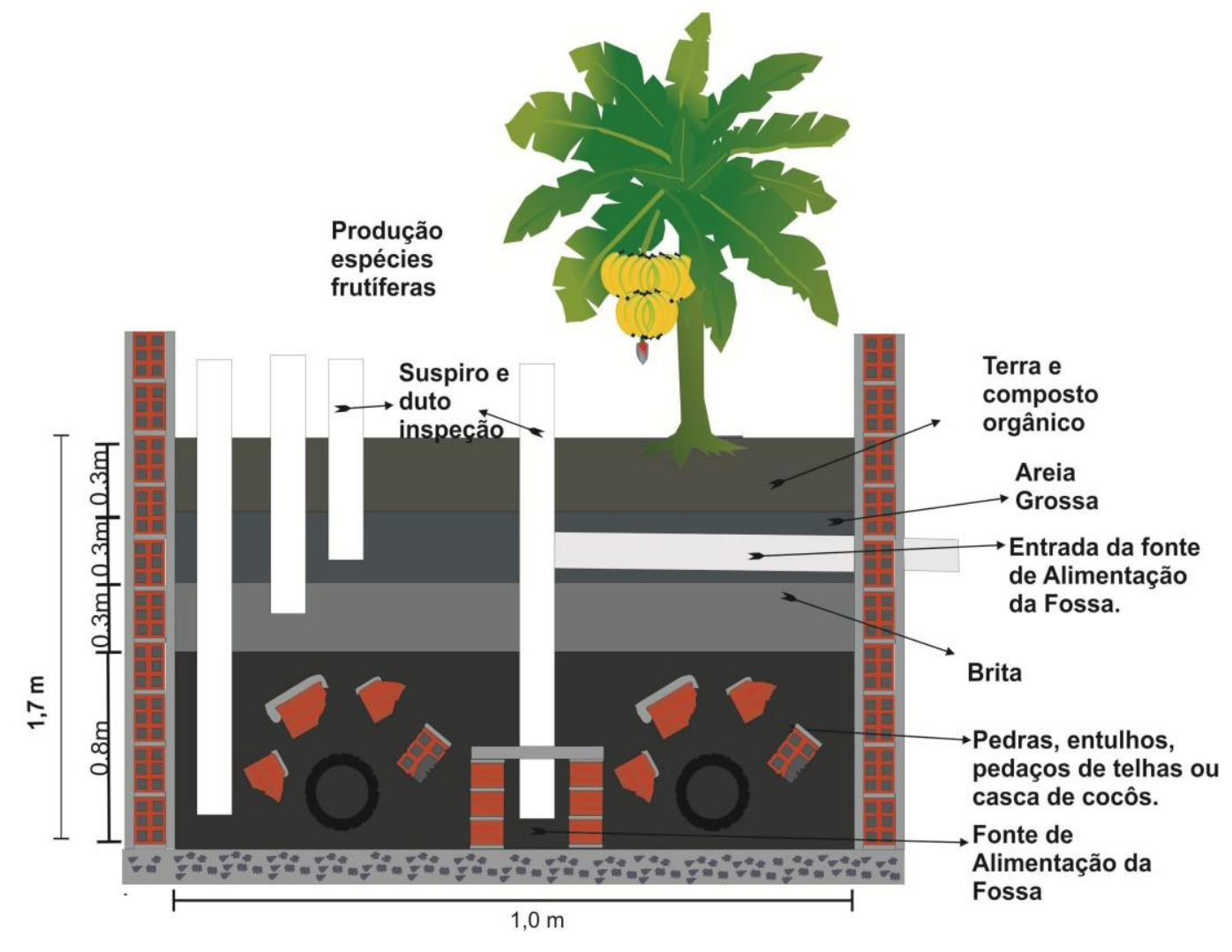

Figura 1 - Esquema do canteiro biosséptico - seção transversal

Fonte: Os Autores 


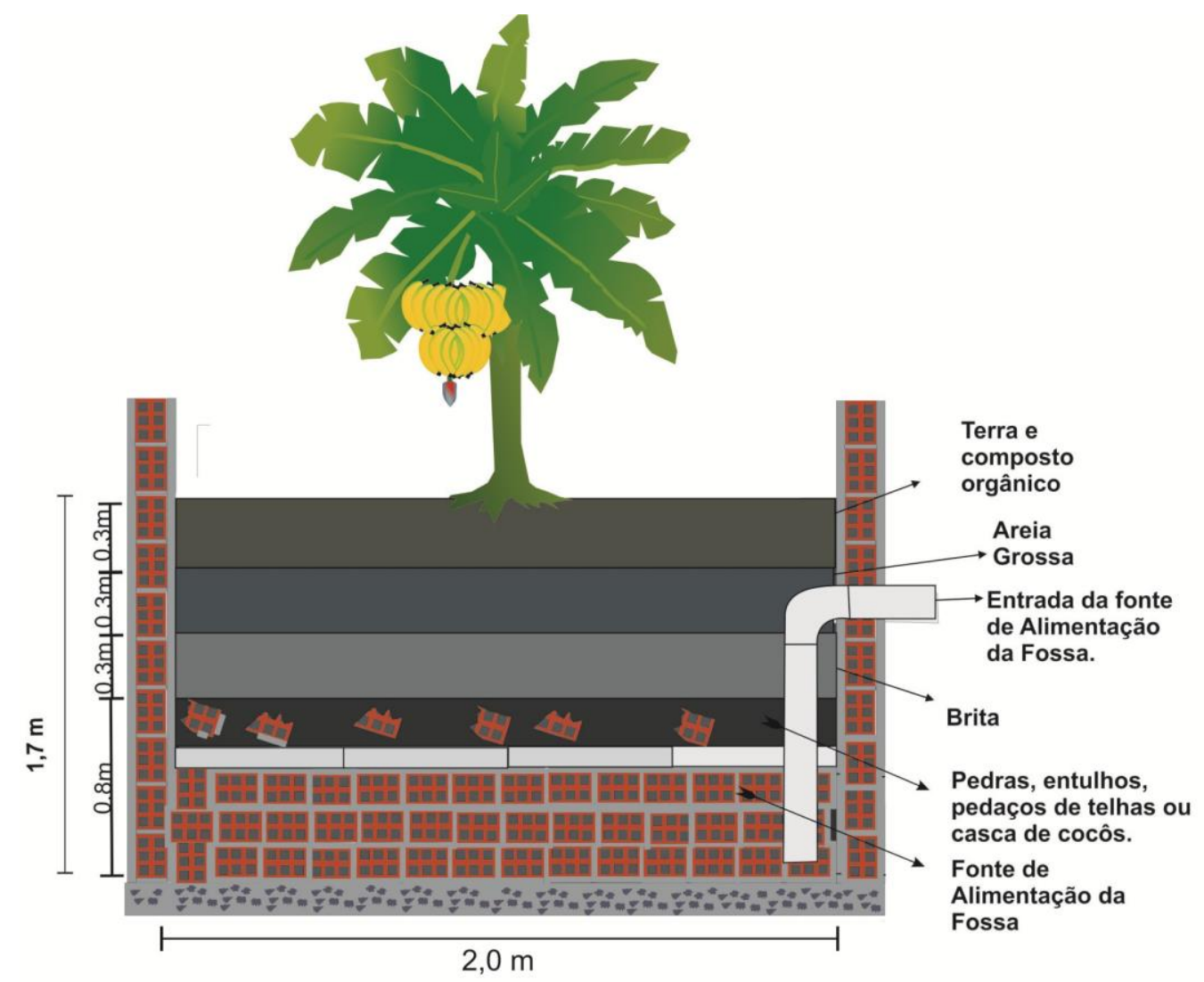

Figura 2 - Corte longitudinal do canteiro biosséptico

Fonte: Os Autores

O canteiro biosséptico foi dimensionado baseado na NBR 7229/1993 que fixa as condições exigidas para projeto, construção e operação do sistema de tanques sépticos, incluindo tratamento e disposição de efluentes e lodo sedimentado. Neste projeto dimensionou-se a fossa para um domicilio de cinco usuários, tendo em vista a média das famílias locais. Dentro da norma, o dimensionamento adotou os maiores índices possíveis de modo a garantir a melhor segurança do sistema proposto. É importante salientar que o dimensionamento pode ser realizado para atender a diversas faixas de usuários e até construção de fossa comunitária, a depender da necessidade e interesse requerido.

De acordo com o dimensionamento realizado chegou-se a um volume útil de $3,4 \mathrm{~m}^{3}$ e dimensões 2,00m x 1,00m x 1,70m (comprimento x largura x profundidade). Buscou-se seguir esse padrão em todas as unidades. No entanto, características intrínsecas de cada comunidade, tais como tipo de solo e nível do lençol freático, condicionou a adoção de alguns ajustes nas dimensões para escavação. No mais, seguiu-se o dimensionamento sugerido. A parte interna da câmara foi preenchida com cascalho grosso na parte inferior, seguindo o preenchimento das camadas posteriores com materiais de granulometria menor, como brita, areia e terra para o plantio.

É importante salientar a necessidade de instalação de dutos que servem de inspeção e coleta do efluente liquido existente no interior da unidade de tratamento. Propõe-se que esses dutos de inspeção sejam colocados em cada camada de material suporte, de modo que possibilite a coleta de efluente para análise ao longo de toda a estrutura da fossa. Durante a digestão anaeróbia da matéria 
orgânica presente no esgoto, o efluente deve ser percolado pelo material suporte (entulhos e agregados) garantindo maior retenção da biomassa e aumentando a eficácia do sistema. Faz-se necessário também colocar um extravasor na parede oposta a da entrada do fluxo de esgoto, visando garantir a saída de eventuais águas em excesso no sistema, a citar caso de alguma chuva intensa.

Com a execução e implantação do sistema, o acompanhamento é fundamental para verificar a eficiência da fossa verde na qualidade de vida e na saúde dos contemplados na região. A comprovação da eficiência do sistema é fundamental para obter novas parcerias e multiplicar a implantação de novas unidades.

Durante o monitoramento inicial do comportamento das fossas verdes será analisada a Demanda Química de Oxigênio (DQO), com frequência semanal, ao longo das camadas filtrantes.

A DQO de uma amostra representa a quantidade de oxigênio necessária para oxidar, através de reação química, material orgânico, particulado ou dissolvido, com dicromato de potássio, em meio de ácido sulfúrico a quente.

O procedimento experimental consiste em adicionar $1,5 \mathrm{~mL}$ da solução de digestão (dicromato de potássio e sulfato de mercúrio) ao tubo de DQO, com o auxílio do dispenser; $3,5 \mathrm{~mL}$ da solução de ácido sulfúrico e sulfato de prata, também com o auxílio do dispenser; 2,0 mL da amostra bruta, senão promover a diluição necessária; preparar a amostra neutra com $2,0 \mathrm{~mL}$ de água destilada; fechar perfeitamente os tubos com tampa apropriada e agitar o conteúdo. Caso a amostra não possa ser digerida imediatamente, deve-se guardá-la sob a proteção da luz.

Na sequência a amostra deverá passar pela etapa de digestão e leitura espectrofotométrica.

\section{RESULTADOS E DISCUSSÃO}

A existência dos serviços de saneamento básico é essencial para o bem estar de toda uma comunidade humana. Tradicionalmente tem sido de responsabilidade, pelo menos no seu gerenciamento, do poder público imperante na coletividade (MOREIRA, 2008). Na realidade, isto não é assegurado. No que diz respeito ao esgotamento sanitário, o estado de Alagoas, mais precisamente os municípios localizados no alto sertão do estado encontram-se numa situação bem preocupante. A situação torna-se evidente na constatação feita nas comunidades que receberam as unidades de fossa verde nos municípios de Mata Grande, Pariconha e Água Branca. Das famílias contempladas $33 \%$ despejavam todos os resíduos a céu aberto, sendo as $67 \%$ destinam parcialmente os resíduos para fossa negra (Figura 3).

O princípio da fossa verde é tratar o esgoto doméstico, para prevenir a contaminação do solo e do lençol freático. A implantação das unidades nas comunidades beneficiou as famílias com a mitigação desses problemas, reduzindo a possibilidade de contaminação do solo e das nascentes, estas utilizadas como fonte de abastecimento de água para os proprietários. A água residuária doméstica cinza ou negra, quando em contato com corpos hídricos podem causar eutrofização.

A fossa verde foi proposta para receber apenas os resíduos domiciliares provenientes da bacia sanitária (água negra). No entanto, devido às condições locais de alguns dos municípios, tais como escassez considerável de água para o consumo e consequentemente do menor volume de água a ser fornecido ao sistema, optou-se por adicionar a ela os efluentes das pias de cozinha e dos ralos de chuveiro (água cinza). Von Sperling (2005) enfatiza que a característica dos esgotos é função dos usos à qual a água foi submetida. Esses usos, e a forma com que são exercidos, variam com o clima, situação social e econômica e hábitos da população. 


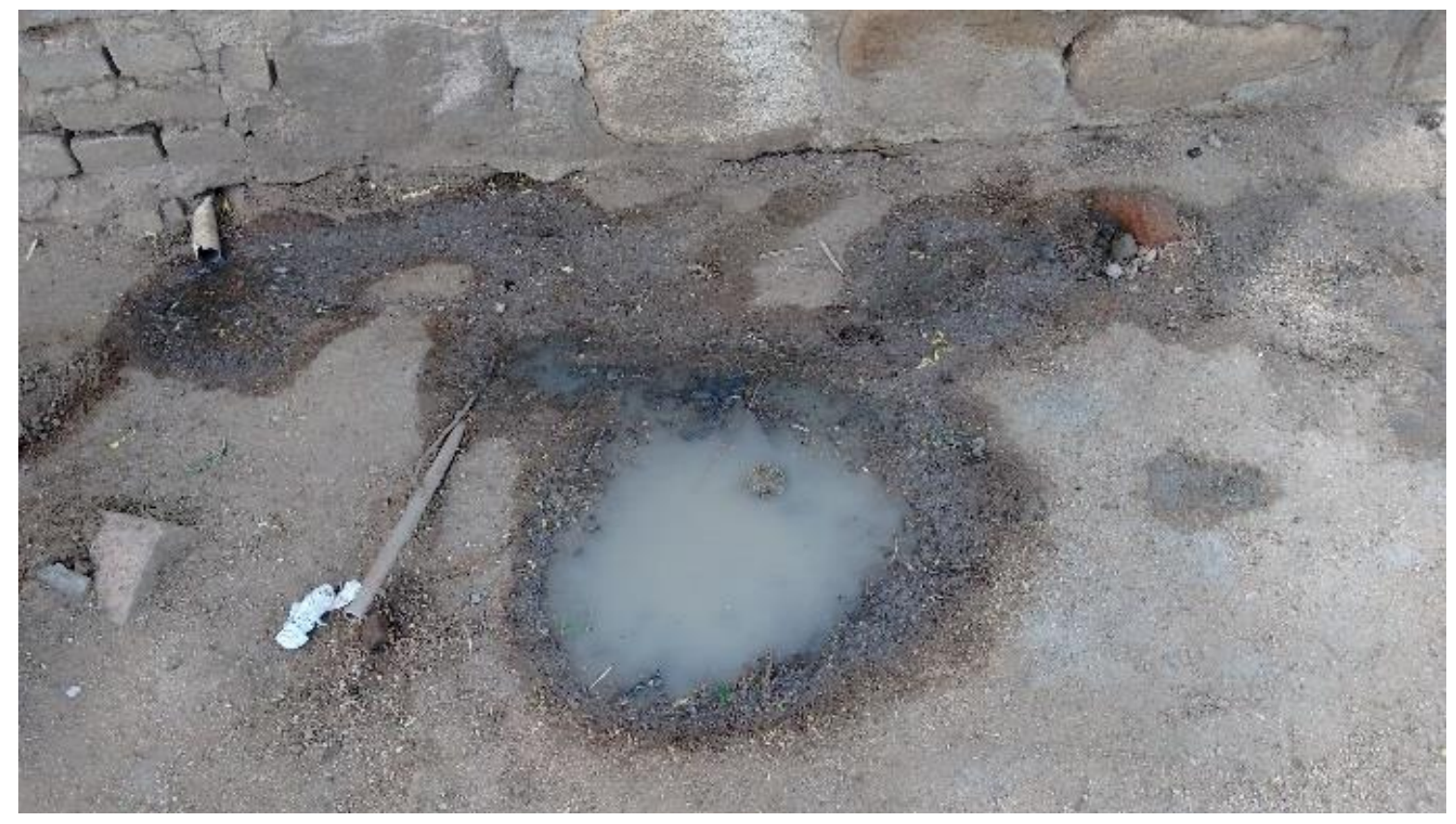

Figura 3 - Esgoto doméstico despejado a céu aberto

Fonte: Os Autores

A água de esgoto possui grande carga em nitrogênio e fósforo que são imprescindíveis para formação de tecidos e produção de energia nas plantas demonstrando a perfeita utilização dos sólidos presentes no esgoto. Na biorremediação vegetal as águas e os compostos nutricionais provindos do esgoto são reaproveitados pelas plantas. A digestão anaeróbia, associada ao tanque séptico, em conjunto com a ação de microrganismos aeróbios na zona de raízes das plantas consome a matéria orgânica proveniente do dejeto domiciliar. A água é evapotranspirada e usada de modo consuntivo pela vegetação (ARAÚJO, 2012).

$\mathrm{O}$ orçamento atual de uma unidade de fossa verde gira em torno de $\mathrm{R} \$ 1050,00$ (mil e cinquenta reais), podendo variar de acordo com alguns fatores como: tamanho da estrutura, quantidade de usuários, mão de obra participativa, características intrínsecas do solo, distância da construção do sistema em relação ao domicílio e etc. A próxima fase da pesquisa constituirá na escolha de quais parâmetros serão adotados para realizar as análises dos esgotos condicionados nas três unidades de fossa verde implantadas. Apesar da fossa verde já ser a destinação final do esgoto, é importante verificar o comportamento da remoção de contaminantes ao longo das camadas suporte para obtenção de dados e possível readequação do projeto para unidades futuras.

A Figura 4 apresenta a sequência construtiva de uma unidade de fossa verde. Destaca-se a necessidade de impermeabilização das paredes de alvenaria no intuito de evitar a contaminação do solo, bem como o cuidado em dispor as camadas filtrantes de forma uniforme e sobrepostas. 


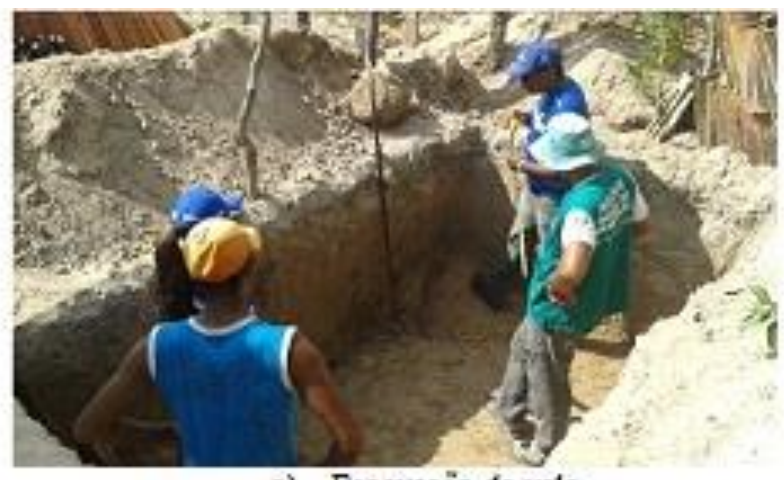

a) Escavaçäo da vala

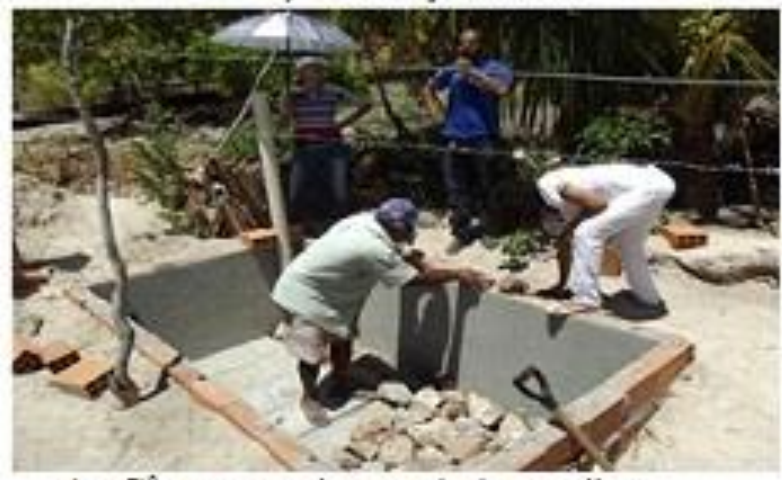

c) Câmara central e camada de cascatho

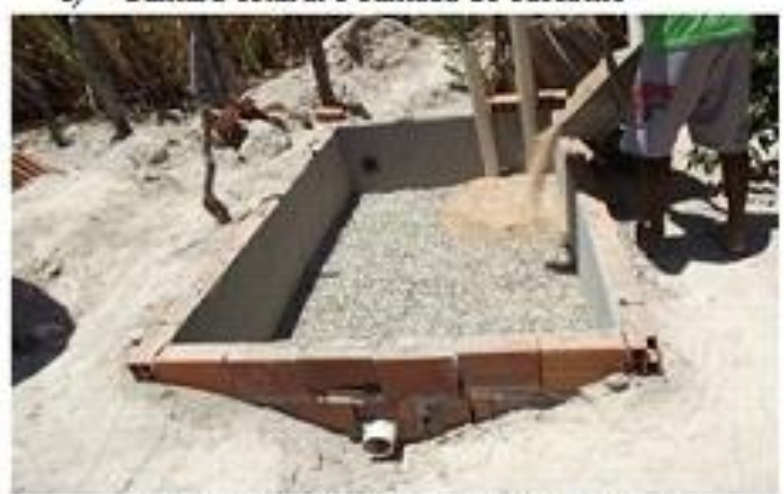

e) Camada de areia grossa sobre a brita

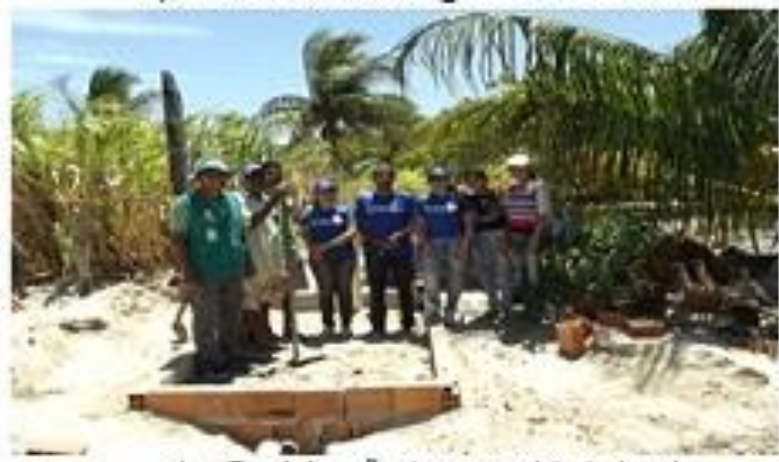

g) Participaçảo da comuridade tocal

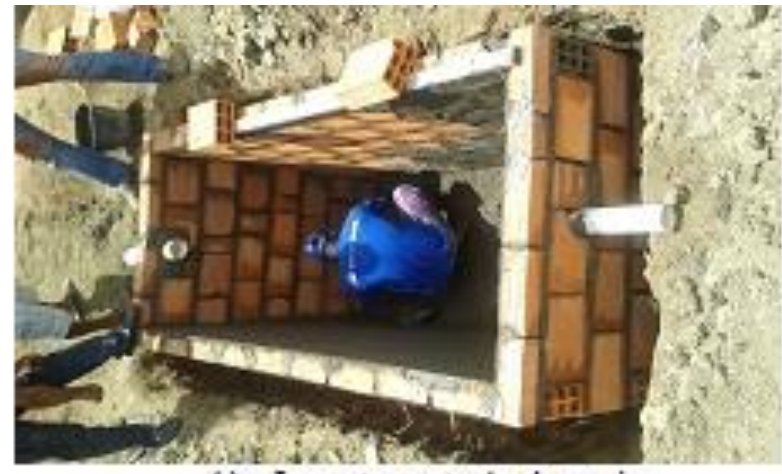

b) Levantamento da alvenaria

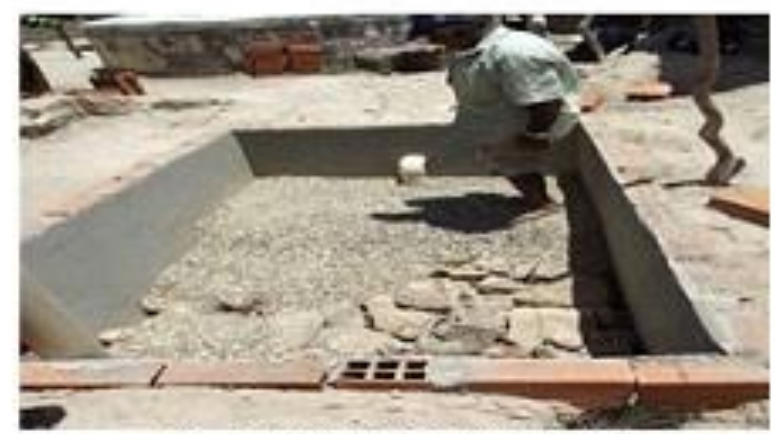

d) Camada de brita sobre o cascatho

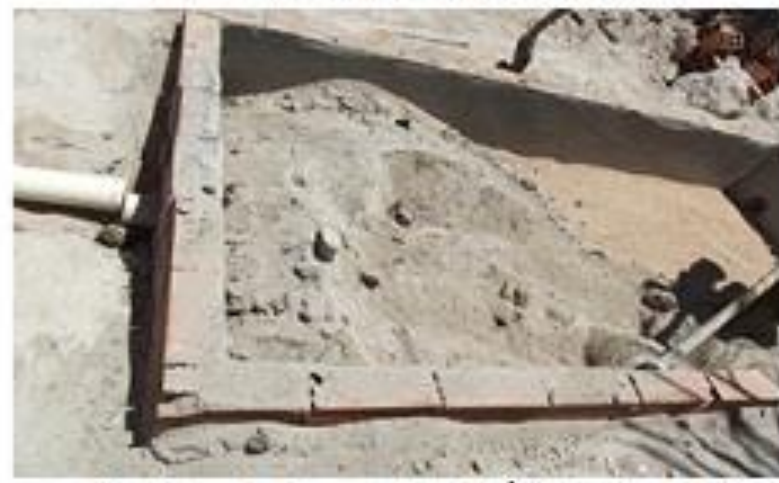

f) Camada de composto orgánico sobre a are ia

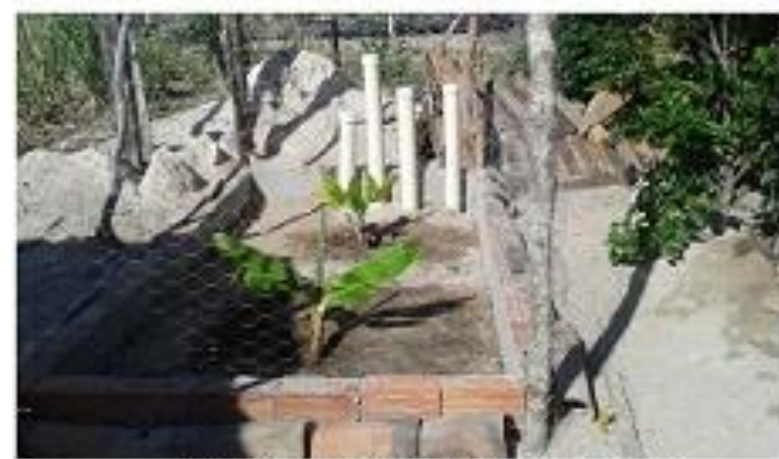

h) Fossa verde em funcionamento

Figura 4 - Etapas construtivas da fossa verde

Fonte: Os Autores 
Na coleta realizada na fossa verde instalada no município de Mata Grande a DQO bruta, da amostra coletada na câmara de alimentação através do tubo instalado, foi de 889,3 mg/L. Já a DQO bruta encontrada para a camada de cascalho que recebe o esgoto proveniente da câmara foi de $550,7 \mathrm{mg} / \mathrm{L}$ (Figura 5).

As demais camadas de brita e areia não apresentaram esgoto a ser coletado, provavelmente pelo pequeno período operacional (7 dias) e consequentemente não tiveram o comportamento em relação a DQO analisado.

A DQO mede o consumo de oxigênio durante a oxidação química de compostos orgânicos presentes numa água. Os valores obtidos são úteis para a avaliação do teor de matéria orgânica de forma indireta. $\mathrm{O}$ esgoto doméstico classificado como forte apresenta valor típico para o parâmetro DQO de aproximadamente $800 \mathrm{mg} / \mathrm{L}$ (Jordão \& Pessôa, 2005), o que indica que a fossa de Mata Grande está tratando esgoto concentrado característico de regiões com pouca disponibilidade hídrica como é o caso da região do alto sertão do estado de Alagoas.

Outra consideração importante é que já na primeira camada filtrante a fossa verde apresentou remoção de aproximadamente $38 \%$ em relação ao esgoto bruto. A Figura 4 apresenta o comportamento para DQO em relação aos pontos de coleta da fossa verde.

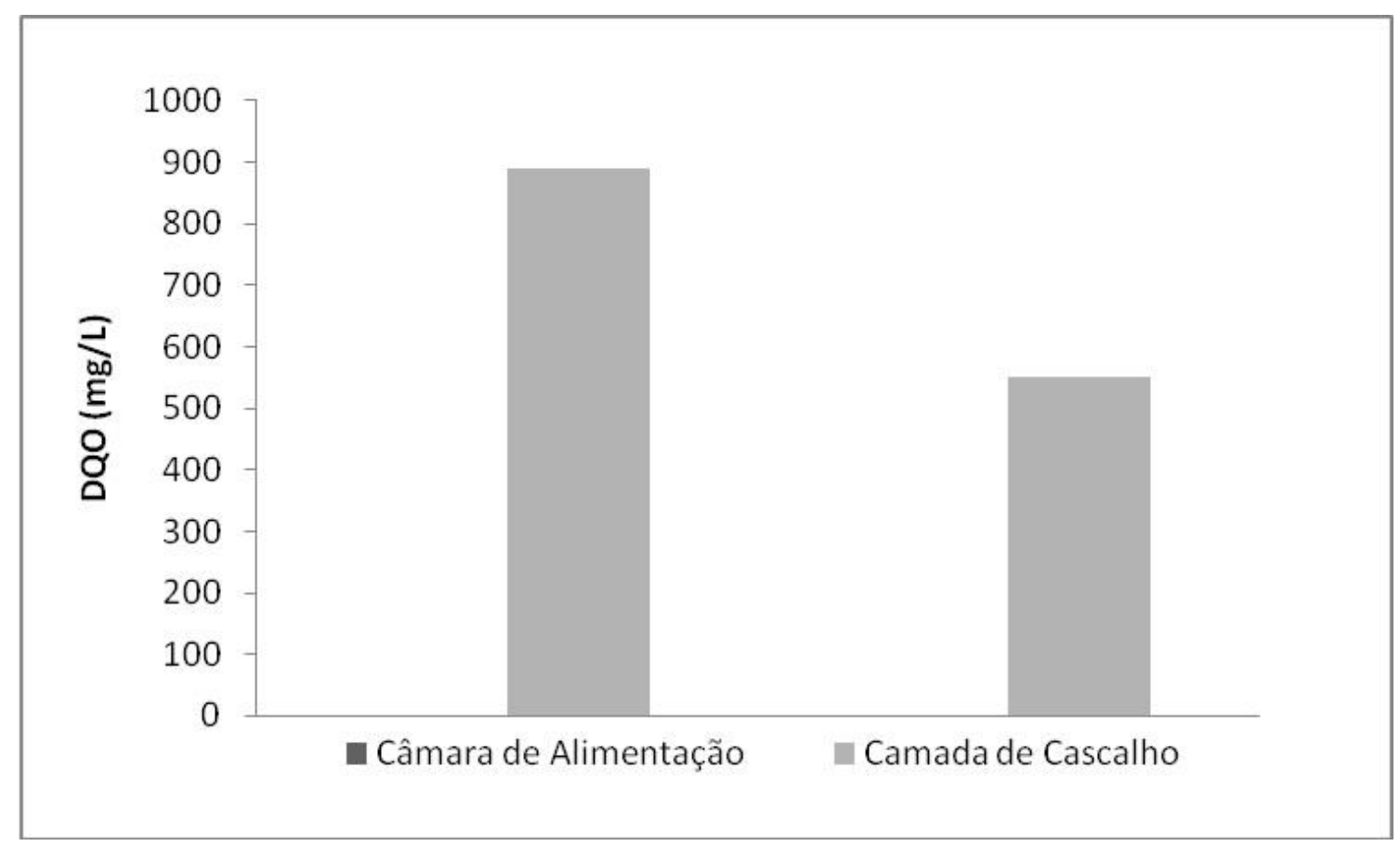

Figura 5 - Comportamento da DQO ao longo da altura da fossa verde

Fonte: Os Autores

As três unidades piloto implantadas constituíram uma experiência muito enriquecedora para os sujeitos envolvidos no processo, população local beneficiada, secretarias municipais, técnicos, discentes e docentes. A interação academia/comunidade proporciona uma troca de saberes e conhecimentos muito rica para o desenvolvimento. Diante da aprovação obtida com a implantação das unidades espera-se firmar novas parceiras para que o índice de unidades seja mais significativo, abrangendo maior número de usuários. 
O projeto tem significativa relevância para os docentes e discentes envolvidos, aprimorando a formação profissional, garantindo diferencial mercadológico e amadurecimento acadêmico. Os projetos de extensão possibilitam aos graduandos a realimentação dos conhecimentos desenvolvidos e em desenvolvimento ao longo do curso, visto que a formação ultrapassa a simples aquisição de conhecimentos técnico-científicos, os quais são praticamente irrelevantes quando não associados à realidade. A extensão proporciona condições para que a formação acadêmica contemple além do conhecimento técnico e institucional, aspectos sociais e políticos.

\section{CONCLUSÃO}

O sistema de biorremediação vegetal apresentado pela fossa verde auxilia na redução de despejos a céu, sobretudo nas comunidades rurais do nordeste, onde costumeiramente os sistemas coletivos de coleta e tratamento de efluentes não conseguem atuar. A confiabilidade observada através da operação de sistemas mais antigos dá respaldo e segurança para firmar tal tecnologia como alternativa viável para condicionamento adequado dos efluentes domésticos, além de constituir uma solução de baixo custo.

A implantação do sistema nos municípios correlatados contribuirá consideravelmente para o desenvolvimento rural, fortalecendo a equidade social e a cidadania através do diálogo entre diferentes saberes (populares e acadêmicos).

Como em todo projeto de extensão, este projeto objetivou fundir o conhecimento aprendido e produzido na universidade e aplicar no desenvolvimento de uma comunidade, contribuindo para a melhoria da mesma. Entende-se que é muito importante a interação academia/comunidade, proporcionando troca de saberes e conhecimentos, incentivando a participação da comunidade, enquanto sujeitos e não como meros espectadores.

\section{AGRADECIMENTOS}

Ao Laboratório de Saneamento Ambiental da Universidade Federal de Alagoas - Campus Sertão, a UFAL - Campus Sede, a Pró-Reitoria de Extensão (Proex), ao Projeto Renas-Ser, as comunidades envolvidas e a Deus.

\section{REFERENCIAS}

ARAÚJO, J. C. "Fossas Verdes" objetivam garantir sustentabilidade no sertão cearense. Disponível em: <http://www.incra.gov.br/index. php/noticias-sala-deimprensa/noticias/11789-qfossas-verdesq-objetivam-garantirsustentabilidade-no-sertãocearense> Acesso em: 11 nov. 2013

DI BERNARDO, Luiz; Dantas, Angela Di Bernardo. Métodos e técnicas de tratamento de água. São Carlos. Rima, 2005.

GABIALTI, A. F. Tratamento domiciliar de águas negras através de tanque de evapotranspiração. Dissertação (Mestrado). Universidade Federal do Mato Grosso do Sul, Campo Grande, 2009.

GAYLARD, C. C., ET AL. Aspectos biológicos e técnicos da biorremediação de xenobióticos. Biotecnologia, Ciência e Desenvolvimento, Brasília/DF, n.34, p. 36-43, 2005.

JORDÃO, Eduardo Pacheco; PESSOA Constantino de Arruda. Tratamento de Esgotos Domésticos. Rio de Janeiro, 2005.

MOREIRA. M. C. Sistemas Urbanos de Esgoto. Empresa Baiana de Águas e Saneamento. EMBASA, 2008. Disponível em: < http://www.ebah.com.br/content/ABAAAfsDYAB/apostila-embasa> Acesso em 01 nov. 2015. 
OLIVEIRA NETTO, A. P., ET AL. Utilização da fossa verde como biorremediação do esgoto domiciliar no estado de Alagoas. In: IV Seminário Internacional de Engenharia de Saúde, 2012.

OLIVEIRA NETTO, A. P. Reator anaeróbio-aeróbio de leito fixo, com recirculação da fase líquida, aplicado ao tratamento de esgoto sanitário. 2007. Dissertação (Mestrado em) Escola de Engenharia de São Carlos, Universidade de São Paulo, São Carlos, 2007.

SISTEMA NACIONAL DE INFORMAÇOES SOBRE SANEAMENTO - SNIS. Diagnóstico dos serviços de água e esgotos. Site institucional, 2013. Disponível em: <http://www.snis.gov.br〉.

TSUTIYA, Milton Tomoyuki, ALEM SOBRINHO, Pedro. Coleta e transportes de esgoto sanitário. UFCE - BCGE, 2000.

VON SPERLING, Marcos. Introdução à qualidade das águas e ao tratamento de esgoto. Belo Horizonte: DESA/UFMG, 2005. 